\title{
Marisa Moromi
}

Doctora en Historia del Programa Historia y Sociedad en las Américas de la Universidad de Sevilla. Becaria de posgrado del Consejo Superior de Investigaciones Científicas de España (CSIC) con sede de trabajo en la Escuela de Estudios Hispanoamericanos de Sevilla. Integrante del Instituto de Estudios Socio-Históricos de la Facultad de Ciencias Humanas en la Universidad Nacional de La Pampa, Argentina. Especializada en historia cultural y política de fines del siglo XIX argentino.

\section{Resumen}

Después de los años setenta del siglo xIx el gobierno argentino se concentró en incorporar al país al circuito económico mundial en la certeza de que ello estimularía la modernización y a su vez facilitaría el desarrollo social. Uno de los objetivos oficiales más importantes apuntaba a maximizar los beneficios de la producción agrícola-ganadera mediante la anexión de las tierras de la frontera interior. De esta forma, el Estado argentino dio paso a la intervención coactiva para hacer efectivo el control real de todo su territorio y su población. El propósito de este texto es desarrollar algunos aspectos constiturivos del proceso de nacionalización de la frontera pampeana. Se examina el conocimiento previo que existía sobre las tierras en el momento de concretar la ocupación del espacio en contraposición con el conocimiento científico y oficial que se fue construyendo a medida que avanzaba la expedición al "desierto". Conocimiento que influyó en los patrones de distribución, organización y administración de la tierra pública a finales del siglo XIX.

Palabras clave:

Formación del Estado, frontera, desierto, nacionalización, territorio, pampeana.

Fecha de recepción: marzo de 2006
Fecha de aceptación: mayo de 2006 


\title{
The Nationalization of the Pampas Border and the Formation of the Argentinean State
}

\author{
Marisa Moroni
}

Ph. D. in History in the History and Society in the Americas Program at the University of Seville. Graduate fellowship holder from the Board of Scientific Research of Spain (CSIC) based in the School of Latin American Studies in Seville. Member of the Institute of Socio-Historic Studies of the Faculty of Human Sciences at the National University of La Pampa, Argentina. Specialist in late 19th century Argentinean cultural and political history.

\begin{abstract}
After the 1870s, the Argentinean government concentrated on incorporating the country into the world economic circuit, convinced that this would foster modernization and facilitate social development. One of the most important official objectives was to maximize the benefits of agricultural and stock-raising production through the annexation of land on the inner border. Thus, the Argentinean state implemented coercive intervention to achieve real

The purpose of this text is to develop certain constitutive aspects of the nationalization of the pampas frontier. It examines prior knowledge of the land at a time when it began to be occupied in opposition to the scientific and official knowledge that was constructed as the expedition to the "desert" advanced. This knowledge influenced the patterns of distribution, organization and administration of public land in the late $19^{\text {th }}$ century.
\end{abstract} control of its entire territory and population.

Key words:

State formation, border, desert, nationalization, territory, pampas.

Final submission: March 2006
Acceptance:

May 2006 


\title{
La nacionalización de la frontera pampeana y la formación del Estado argentino
}

\author{
Marisa Moroni
}

INTRODUCCIÓN

$\mathrm{G}$ n los últimos quince años, comenzó una renovación profunda en los estudios e interpretaciones del pasado político argentino. Especialmente surgió un interés en "el Estado", tanto como un objeto de investigación o como algo a lo que se recurre para explicar resultados. El Estado, como actor o como institución, potenció la proliferación de estudios que, encarados desde distintas perspectivas teóricas, han ganado terreno en la historiografía argentina. ${ }^{1}$

Atrás han quedado las interpretaciones realizadas en términos de una transición progresiva de la sociedad colonial al Estado moderno que enfocaban los avances y retrocesos en el camino hacia un destino nacional.

En recientes investigaciones, la mirada es otra, pues se interroga por los diferentes proyectos y ensayos de formación y ordenamiento político-social de las nuevas comunidades políticas durante la segunda mitad del XIX. Se examina el papel del Estado como un promotor de reformas políticas, o del desarrollo económico na-

${ }^{1}$ Brennan y Pianetto, Region, 2000; Sabato y Lettieri, Vida, 2003, y Chiaramonte, Nación, 2004. cional, y también como un regulador de los cambios en la estructura social. ${ }^{2}$

De acuerdo con la argumentación weberiana que concibe al Estado como una organización que reclama compulsivamente para sí el control sobre su territorio y su población, este puede formular objetivos que no siempre son el reflejo de las demandas o intereses de los grupos sociales a los que afecta. En este sentido, una de las metas principales que se plantearon los "ideólogos del progreso y la civilización" durante del proceso de formación del Estado argentino fue la apropiación de las enormes extensiones de tierra ubicadas al sur del río Salado y de los recursos productivos que ellas albergaban, hasta el momento "desaprovechados" por las comunidades indígenas. En definitiva, se trataba de dotar al Estado de una nueva y más sólida financiación basada en los resultados de los gravámenes al comercio exterior, que dependía directamente de las exportaciones rurales.

La estancia ganadera se revelaba como una de las formas más dinámicas para expandir la producción extendiendo el dominio sobre las tierras indígenas. Después

${ }^{2}$ González, Civilidad, 2001; Bertoni, Patriotas, 2001, y Devoto, Nacionalismos, 2002, entre otros. 
de la segunda mitad del siglo XIX, la nacionalización de las tierras de la frontera, el establecimiento del orden, la sanción de derechos de propiedad y la creación de una red de transportes y comunicaciones para trasladar la producción fueron ámbitos en los que el Estado reflejó su apoyo a la expansión del capitalismo y la gran propiedad. ${ }^{3}$ Estas acciones se vieron favorecidas por la una paulatina calma en el orden político después de la caída de Rosas en 1852, que permitió dirigir la atención hacia la expansión de la proḍucción agraria y la transformación económica. A partir de 1870 , con un Estado con sólidas bases políticas comenzó a evidenciarse un dinamismo económico asociado a la producción rural que favoreció el consenso para abocarse a la tarea de liberar la Pampa de los indígenas y sumar así estas tierras a la producción.

Para concretar la nacionalización de las regiones de frontera se requería una infraestructura estatal y un volumen de inversiones que no siempre estaban al nivel del desafío propuesto. La única certeza que guiaba los proyectos de la dirigencia política argentina se apoyaba en la necesidad de ampliar el mercado nacional y reconducir las riendas de la economía hacia el modelo capitalista agroexportador. ${ }^{4}$ Estos cambios producirían un aumento en las oportunidades y en la dimensión de los negocios. Por lo tanto, no resultaba lógico disponer de un capital abundante, como las tierras al otro lado de la línea de fortines que culminó con la operación militar denominada Campaña del Desierto.

A partir del año 1878, una sucesión de leyes nacionales y decretos presiden-

\footnotetext{
${ }^{3}$ Hora, "Empresarios", 2003.

${ }^{4}$ Halperin, Historia, 1975; Proyecto, 1980, y Botana, Orden, 1997.
}

ciales autorizó y legitimó las incursiones militares a la frontera con el objetivo de expropiar las posesiones indígenas y reafirmar la soberanía en estos espacios. ${ }^{5}$ El éxito de la extensión de la frontera productiva iba más allá del control militar de las tierras y estaba fuertemente asociado a la capacidad estatal para movilizar y disponer de recursos que de forma constante y creciente garantizaran el éxito del modelo productivo en marcha. De esta forma, se avanzaría paulatinamente en "la escala del progreso en la ocupación del suelo", como se denominó a la gradación de espacios diferenciados del territorio argentino. ${ }^{6}$

El punto de partida para la nacionalización de las tierras fue la ampliación de la línea de frontera hacia el este de la provincia de Buenos Aires. Ello conllevó la expropiación de las posesiones de los pobladores originarios que allí habitaban: los indígenas de las regiones pampeanopatagónicas. Una vez concluida la expedición, las áreas "liberadas" fueron anexadas como tierras fiscales para luego cederlas en venta o como pago de los aportes realizados por grandes propietarios que financiaron la Campaña del Desierto. La expedición anexó a la soberanía argentina un total de 500000 kilómetros cuadrados de extensión que se promocionaron como tierras libres y nacionales.

Al momento de la entrada militar a la frontera pampeana existía un conocimiento parcial y sesgado de las características de las tierras a ocupar. Circulaba una especie de idealización de las bondades de las regiones por descubrir. Por ello, algunos sectores profetizaban que sólo bastaba arrojar una semilla para descubrir las ca-

\footnotetext{
${ }^{5}$ Gadano, Territorios, 1945.

${ }^{6}$ Oszlak, Formación, 1999, p. 133.
} 
racterísticas prolíficas de las tierras, así lo ratificaba la prestigiosa publicación de la Sociedad Rural Argentina en el año 1877:

La Pampa bajo el imperio del trabajo sería la tierra de promisión. Esas grandes llanuras casi todas compuestas de terrenos̀ ricos en humus y en principios alcalinos, humedecidos en los rigores del estío con el inmenso caudal de agua que la recorre interiormente como un sistema arterial; sus estaciones perfectamente caracterizadas [...] todo ello demuestra condiciones especiales para diversidad de productos agrícolas. ${ }^{?}$

A medida que fue avanzando el ejército fue necesario contar con un equipo de especialistas que se encargaron de construir mapas, estudiar la topografía del lugar y realizar estudios climatológicos y geológicos para brindar certezas y actualizar las escasas descripciones que circulaban y que fueron realizadas por los viajeros en la primera mitad del siglo XIX. Por primera vez ciencia y tecnología se implicaban en el proceso de incorporación de tierras a la soberanía nacional. La promesa de futuras riquezas adquiría más peso si estudios científicos avalaban la información disponible. ${ }^{8}$ Asimismo, ciencia y tecnología se unían para resaltar los valores altruistas de los conquistadores y los colonizadores que redescubrían unas tierras que permanecían al margen de la civilización, evitando cualquier referencia a los anteriores ocupantes.

7 Anales de la Sociedad Rural Argentina, vol. XI, 1877, Buenos Aires, p. 81, en Biblioteca del Congreso de la Nación (en adelante $\mathrm{BCN}$ ).

${ }^{8}$ Un estudio sobre el impacto de la ciencia y la tecnología en la ocupación de tierras en el caso inglés en Drayton, Nature's, 2000.
El proceso de incorporación de los espacios fronterizos incluyó la puesta en producción de las tierras y su posterior repoblamiento. Ello se realizó mediante un acelerado y caótico reparto que fue responsable del movimiento especulativo y el consiguiente encarecimiento del valor de las propiedades en más de $500 \%$. Una consecuencia inmediata de la especulación fue el arrendamiento precario de pequeñas posesiones que se convirtió en el régimen de tenencia más extendido durante esta primera etapa. ${ }^{9}$

A la distribución de la tierra le siguió la apertura de caminos, la habilitación de mensajerías, el tendido de líneas férreas para comunicar la región con la zona portuaria, la fundación de pueblos y el establecimiento de entidades bancarias para financiar la producción de los primeros agricultores pampeanos. Es en este contexto en el que las sociedades "de frontera", legalmente denominadas Territorios Nacionales, van a desempeñar un papel indudable en la constitución de la nación argentina.

\section{LA FRONTERA INTERNA COMO UNA CUESTIÓN DE INTERÉS NACIONAL}

La formación del Estado en Argentina puede considerarse como el efecto resultante de una combinación de procesos estructurales concretos con decisiones políticas estratégicas que poco a poco fueron apropiándose y reglando todo el entramado social sobre el que actuaba. ${ }^{10}$ Podemos

9 Guérin, "Consecuencias", 1980; Mayo, "Riel", 1980, y Maluendres, "Condicionantes", 1993.

${ }^{10}$ Sobre la temática referida a las transformaciones, estrategias y políticas públicas desarrolladas durante la consolidación de los Estados nacionales véase Tilly, Coerción, 1992. 
decir que la unificación del territorio asumió un papel fundamental como factor aglutinante de la representación simbólica y física de la sociedad argentina. ${ }^{11}$

A finales del siglo XIX, la política gubernamental estaba orientada a transformar una población dispersa y segmentada en una nación homogénea que abrazaba los ideales del progreso, la modernización y el desarrollo social. En este sentido, el año 1880 fue decisivo para resolver el "problema fronterizo" y para establecer de manera imperativa la consolidación de la nación argentina. El Estado ejerció aquello que consideraba su prerrogativa inalienable: la ocupación efectiva de los espacios extraprovinciales. Básicamente, mediante la coacción organizada se redefinieron los límites geopolíticos del territorio en toda su extensión.

En el discurso de la intelligentsia nacional, las áreas fronterizas reflejaban una imagen que simbolizaba un espacio caracterizado por la ausencia o escasez de blancos. Era la zona no civilizada, es decir: el "desierto". ${ }^{12}$ Se creó así una representación oficial de las regiones ocupadas por las comunidades indígenas que negó cualquier tipo de autoridad o potestad que no fuera la estatal. Los indígenas pampeanos, habi-

${ }^{11}$ Quijada, Bernand y Schneider, Homogeneidad, 2001, y Argeri, Guerreros, 2005.

${ }^{12}$ El término desierto comienza a utilizarse en escritos del siglo xviII como adjetivo o sustantivo que implica una metáfora. Es atribuido al desconocimiento geográfico y por tradición se lo siguió utilizando aun después de comprobar las características de las regiones a las que hacía referencia. Algunos autores indican que el vocablo desierto debe emplearse únicamente para designar las tierras que habitaban los indígenas e identificarse con morada o escenario de despoblación y específicamente con la inexistencia de población blanca. Castellán, "Nacimiento", 1980, p. 293 tantes originarios de la región, personificaban un estadio evolutivo inferior que sólo podía remediarse con la inmediata intervención del ejército. Los altos mandos militares habilitaron el uso de la violencia y la marginación como recursos válidos para concretar la territorialización en forma nacional de las regiones fronterizas. ${ }^{13}$

En este periodo, el debate acerca del origen de la identidad nacional y la búsqueda del progreso material se convirtieron en grandes ejes de los programas políticos, en la retórica oficial y en el horizonte de una dirigencia que proclamaba la necesidad ontológica de asumir el control efectivo de la totalidad del espacio perteneciente a la nación. La frontera interior pasó a formar parte de un vasto cuerpo de riqueza sin propietarios. Ciertamente, para las comunidades indígenas el impulso nacionalizador conllevó un alto costo en vidas humanas, la pérdida de derechos y el abandono involuntario de tierras, bienes y trabajo. ${ }^{14}$

Los documentos de los viajes de exploración realizados por los militares y científicos que recorrieron la frontera pampeana, la describieron como un territorio vacío con un paisaje natural intacto que poseía inmejorables condiciones para la producción. ${ }^{15}$ En cambio, los estudios actuales revelan una realidad diferente a la promocionada a mediados del siglo xIx. Hoy sabemos que se trataba de un espacio trabajado y modificado durante años, con patrones de uso de la tierra y colonización muy diferentes a los que surgieron con el repoblamiento que se produjo después de

${ }^{13}$ Quijada, Elites, 2002.

${ }^{14}$ Riekenberg, "Aniquilar", 1996; Quijada, "Ciudadanización", 1999; Eberle e Iribarren, "Estrategias", 2000, y Paredes, "Cuentas", 2003.

1s Navarro, "País", 1999. 
la ocupación de la frontera. ${ }^{16}$ La ceguera ambiental que caracterizó a la mayoría de los análisis dedicados a la temática fronteriza en Argentina omitió la influencia de los pueblos indígenas que la habitaron antes de la llegada del ejército nacional. Por el contrario, se extendió una imagen que describió estos espacios como una sucesión darwiniana que avanzaba de ocupantes y usos de la tierra de un estadio primitivo a otro civilizado.

Las regiones geográficas que se anexaron comprendían importantes extensiones que en total sumaban un espacio mayor a la superficie ocupada por las catorce provincias fundacionales. ${ }^{17}$ Por lo tanto, la cuestión del "desierto" imponía una solución inmediata que debía ser ratificada por los distintos sectores sociales del país. Especialmente por los encargados de autorizar la operación militar destinada a integrar las tierras bajo el dominio estatal. Con el objetivo de ocupar estas regiones, se emprendieron numerosas exploraciones de reconocimiento, se iniciaron tareas de mensura, confección de mapas geográficos, geológicos y estudios topográficos para evaluar su potencial productivo. Asimismo, una comisión de viajeros se encargó de explorar el terreno y de catalogar las especies animales y vegetales de cada ambiente, en especial aquellas que no poseían registros en los espacios geográficos conocidos.

La definitiva apropiación de las tierras llegó con el proceso de institucionalización

\footnotetext{
${ }^{16}$ Mandrini, “Desarrollo”, 1987, y Palermo, “Innovación”, 1988.

${ }^{17}$ Las catorce provincias argentinas fundacionales fueron: Buenos Aires, Catamarca, Córdoba, Corrientes, Entre Ríos, Jujuy, La Rioja, Mendoza, Salta, San Juan, San Luis, Santa Fe, Santiago del Estero y Tucumán.
}

de los espacios extraprovinciales caracterizado por un alto nivel de improvisación y desconexión entre la instancia nacional y la local. Situación que respondió a la urgencia por ocupar, repoblar e iniciar la producción en los Territorios Nacionales y de esta forma liberar al Estado de las exigencias presupuestarias que una empresa de semejante dimensión requería. ${ }^{18}$

En el año 1884, una vez finalizada la Campaña del Desierto, se sancionó la Ley $1532,{ }^{19}$ encargada de organizar los Territorios Nacionales en nueve gobernaciones: Chaco Chubut, Formosa, Misiones, Neuquén, La Pampa, Río Negro, Santa Cruz y Tierra del Fuego. Estas unidades administrativas debían atravesar una etapa tutelada de "aprendizaje cívico y moral" para que sus habitantes pudieran adquirir la aptitud necesaria para establecer un gobierno propio y constituir "futuras provincias argentinas donde antes sólo había desierto". ${ }^{20}$

Los Territorios Nacionales como divisiones administrativas subestatales situadas fuera de las fronteras provinciales asumían un carácter temporario por ser una división ex lege de la nación, es decir, derivada de la creación de una ley específica. Su legislación y jurisdicción estaban sometidas al poder del Estado, que monopolizaba la creación del derecho y de la justicia a través de los órganos y de las reglas por él fijadas. Las máximas fuentes del poder territorial debían estar bajo la protección

${ }^{18}$ Moroni, "Delicado", 2005.

${ }^{19}$ Ley 1532 (980), Organización de los Territorios Nacionales, Anales de Legislación Argentina, Buenos Aires, 1881-1888, en Biblioteca del Superior Tribunal de Justicia de La Pampa (en adelante BSTJ), La Ley, leg. 1074-2440.

${ }^{20}$ Mabragaña, Mensajes, 1910, p. 235. 
del poder estatal, esto suponía un importante condicionamiento a la hora de iniciar el proceso de institucionalización, más aún considerando las distancias que aumentaban la incomunicación entre el centro del poder estatal y las capitales territoriales.

En los Territorios Nacionales la situación de contacto casi habitual entre los que llegaban para repoblar estas áreas, las comunidades indígenas y los habitantes de las provincias limítrofes, condujo a la apropiación mutua de elementos y costumbres que favorecieron la aparición gradual de formas complejas de relación. Esta interacción estuvo reforzada y enriquecida por el constante intercambio entre los distintos componentes de la "nueva" sociedad, en la que estaban incluidos inmigrantes europeos. ${ }^{21}$

La frontera se modificaba y ampliaba a través del tiempo y a medida que se superaban las distintas etapas de crecimiento por las que atravesaba la región. Se pasó de la expropiación al reparto de la tierra pública, de la expansión de la actividad ganadera a la agrícola, y del progresivo arribo de inmigrantes - primero nacionales y luego extranjeros- a la organización política y administrativa de los incipientes poblados. Se trataba de un espacio con una dinámica propia, una "frontera viva" que en el discurso político nacional se erigió como un referente promisorio para unificar un país que arrastraba una historia de profundas divisiones regionales. El tiempo demostró que la verdadera incorporación sólo se produjo en los encendidos escritos y proyectos de la dirigencia nacional. A corto plazo, el modelo de expansión, basado en el triunfo de la "civilización" sobre la "barbarie", naufragó en una crisis estruc-

${ }^{21}$ Quijada, “Repensando”, 2002. tural que afectó económica y políticamente la pretendida unificación nacional. ${ }^{22}$

En este confuso panorama, lo que estaba destinado a perdurar y a consolidarse fue la movilización y la lucha política de quienes repoblaron los Territorios Nacionales esperanzados en acceder a una estructura de poder autónoma y a la potestad sobre los recursos productivos de las tierras que ocupaban.

\section{LA REGENERACIÓN DEL DESIERTO. PRIMERAS REPRESENTACIONES DE LA FRONTERA}

A mediados del siglo XIX, se fortaleció en el Río de la Plata la concepción ilustrada del estímulo a la agricultura cuyo antecedente más concreto derivó de las publicaciones de los fisiócratas europeos de principios de siglo. Para los partidarios de esta corriente de pensamiento, la presencia del indio entrañaba un importante obstáculo para los proyectos modernizadores en los que la tierra era el principal activo nacional.

Un territorio inmenso y rico, ocupado por una población dispersa, autónoma y presuntamente peligrosa, requería una intervención rápida y eficaz por parte de las fuerzas estatales. En el imaginario nacional, la llanura pampeana evocaba fértiles llanuras con recursos naturales que permanecían sin explotar. A esta condición se sumaba la proximidad a puertos oceánicos que le concedía a la región un carácter único en el mundo. Tal como lo señalaba el presidente Julio Roca en el mensaje inaugural del periodo de sesiones del año 1881:

${ }^{22}$ Bragoni, “Gobierno”, 2003. 
Puede asegurarse que no hay al presente nación alguna en el orbe que tenga una extensión tan grande de tierra baldía, bajo climas benignos aunque varios, casi toda litoral o de fácil acceso por el mar o ríos navegables, y susceptible de todos los cultivos [...] la fertilidad de esta Suiza argentina con sus grandes lagos de agua dulce, con sus valles cubiertos de gramíneas y sus bosques de pinos [...] con la desaparición de las tribus de indios salvajes que se enseñoreaban de las dilatadísimas y verdes praderas, que podemos llamar nuestro far West, la población ganadera de las cinco provincias que limitan este territorio, empieza a desbordarse sobre él, y sus tierras. ${ }^{23}$

Asimismo, cronistas y viajeros europeos, volcados a describir las regiones beneficiadas por las reformas borbónicas relacionadas con el libre comercio, divulgaron la existencia de unas planicies extraordinariamente prolíficas ubicadas más allá de la frontera bonaerense. Sus relatos abundaban en generalizaciones y se concentraban en el análisis de la zona ganadera del Litoral y de Buenos Aires, donde la producción lideraba el crecimiento económico de la región. En estas crónicas no se registraron las diferencias intrarregionales, ni las características de las tierras disponibles de acuerdo con la aptitud para soportar un modelo productivo basado en la explotación agrícola-ganadera. ${ }^{24}$

La construcción de un conocimiento científico real de las tierras ubicadas al otro lado de la línea de fortines sobrevino en la última década dèl siglo XIX, al tiempo que se efectuaba la expedición militar para su incorporación. Mientras tanto,

\footnotetext{
${ }^{23}$ Mabragaña, Mensajes, 1910, pp. 37-38.

${ }^{24}$ Sempat, "Sector", 1978, y Garavaglia, "Economic", 1985.
}

existió una idea preconcebida de las tierras de la frontera interior, una representación que las emplazaba como el ámbito elegido para multiplicar los beneficios de la producción destinada a los mercados europeos. En este sentido, el comisionado para el estudio de los Territorios Nacionales afirmaba:

Si hay algo que se impone, tratándose de los territorios nacionales, es el pensar en su porvenir, está en la conciencia pública que [...] en todos ellos se halla lo que el hombre puede necesitar para vivir, sea como bondad de clima y fertilidad de tierra, sin querer mencionar otras condiciones fundamentales para la existencia humana, o como lo factores de felicidad en la vida moral. ${ }^{25}$

El carácter móvil y abierto de la frontera pampeana sumado a unas presuntas condiciones agroecológicas óptimas estimuló una imagen destinada a perdurar hasta el momento de la ocupación de la región. La de un bucólico paisaje donde las tierras libres se convertían en una excelente oportunidad para los que llegaban a repoblarlas. Esta construcción del "lugar ideal" se reflejaba en los discursos políticos y en la descripción de la elite ilustrada de fines del siglo xIX. Un ejemplo de ello es el alegato publicado por el poeta Olegario Andrade en la Revista de la Sociedad Geográfica Argentina. El autor destacaba la conveniencia de estimular la colonización y animaba a los legisladores a impulsar un proceso organizado de ocupación para obtener el máximo rendimiento de las riquezas naturales allí existentes. En un pasaje del extenso escrito, el autor advertía:

${ }^{25}$ Informe de Carlos Gallardo, noviembre de 1935, p. 3. en BCN. 
Como se ve, no hay en el mundo un territorio más vasto ni más apto para la colonización que el nuestro. Tengamos paz y tendremos población. La corriente humana busca las costas tranquilas, no los cabos tormentosos. ${ }^{26}$

$\mathrm{AI}$ incorporarse las áreas fronterizas a las redes económicas mundiales centradas en la exportación agropecuaria a países industrializados, las estructuras económicas y sociales preexistentes fueron eliminadas violentamente. ${ }^{27}$ La modernización como una dinámica socioeconómica intranacional no armonizaba con la presencia de indígenas. ${ }^{28}$ Aunque muy pronto la incompatibilidad se extendió a otros sectores de la población, como los provincianos pobres y sin formación. A modo de ejemplo, Juan Bautista Alberdi afirmaba:

sin población y sin mejor población que la que tenemos [...] todos los propósitos quedarán ilusorios y sin resultados [...] para poblar el desierto son necesarias dos cosas capitales: abrir las puertas de él para que todos entren y asegurar el bienestar de los que en él penetran: la libertad a la puerta y la libertad dentro. $^{29}$

${ }^{26}$ Revista de la Saciedad Geográfica Argentina, t. I, 1881, Buenos Aires, p. 58, en Archivo General de la Nación (en adelante AGN).

${ }^{27}$ Ciertamente podemos notar que las relaciones económicas transnacionales en desarrollo siempre han influido poderosamente en el desarrollo económico argentino y en este sentido el destino de los pueblos indígenas fue determinado por la estructura general y por la fuerza del mercado de un "sistema capitalista universal".

${ }^{28}$ Un estudio de la reubicación de los indios ranqueles después de la campaña militar (1879-1885) en Lluch, "Largo", 2002.

${ }^{29}$ Alberdi, Bases, 1943, pp. 109-111.
Una vez iniciada la ocupación efectiva del espacio, a partir de 1884 , la realidad demostraba que sólo una estrecha faja de tierra ubicada al este de la provincia de Buenos Aires, correspondiente a la actual provincia de La Pampa, respondía a las características de fertilidad y aptitud que pregonaban los mentores de la necesidad de ocupar las tierras para maximizar los beneficios de la producción ganadera de las provincias limítrofes. ${ }^{30}$ En este espacio se concentró $90 \%$ de la población, $96 \%$ de los cultivos y $80 \%$ del ganado vacuno. Esta banda oriental de tierra productiva se extendió desde el meridiano $5^{\circ}$ hasta la isoyeta de los 500 milímetros anuales de lluvia, y allí llegaron las inversiones, como ferrocarriles y caminos para trasladar la producción a la zona portuaria. ${ }^{31}$

En el año 1889, Hilarión Furque escribía en la Revista de la Sociedad Geográfica Argentina una somera descripción de los pésimos resultados productivos de las tierras ubicadas al sur del río Colorado:

Verdad es que se han trazado colonias, pero en terreno totalmente inútil para la agricultura, mientras no sea dotado de canales de riego, por cuya razón los colonos se han retirado al día siguiente de llegar al terreno, pensando sin duda que habían sido engañados, y sin imaginarse que a su vez lo había sido el gobierno [...] el presidente una vez retirado del mando se ha olvidado hasta de averiguar el éxito que da para seguir o no el mismo sistema. ${ }^{32}$

${ }^{30}$ Dodds, "Geography", 1993.

${ }^{31}$ Para complementar la información acerca del desarrollo de la zona oriental pampeana, véase Maluendres, "Agricultores", 1995.

${ }^{32}$ Revista de la Sociedad Geográfica Argentina, t. viI, cuadernos LXIX-LXX, 1889, Buenos Aires, p. 194, en $\mathrm{BCN}$. 
Las expectativas iniciales que ayudaron a la dirigencia nacional a obtener el respaldo parlamentario y los recursos económicos necesarios para la operación militar fueron decayendo. Ante sus ojos se presentaba un nuevo panorama que requería la modificación inmediata del modelo productivo ideado para las nuevas tierras. $\mathrm{O}$ en su lugar, exigía la multiplicación de las partidas presupuestarias destinadas a proveer de infraestructura y recursos para modernizar y potenciar el sector de explotación agrícola, que además demandaba mayor inversión que la ganadera. En las primeras décadas del siglo $\mathrm{Xx}$, entre los círculos políticos y militares existía un sentimiento generalizado de fracaso y pesimismo relacionado con la capacidad y características naturales de las regiones nacionalizadas. Era el momento de reconocer que al iniciar la empresa de extensión de las fronteras, los promotores de la unificación territorial poseían un conocimiento vago y uniforme de lo que existía más allá del "límite de la civilización".

$\mathrm{La}$ anunciada potencialidad de los Territorios Nacionales pronto se volvió un espejismo y resurgió una representación negativa de estos espacios que justificaba el abandono del proyecto original. El legislador Joaquín González reconocía las diferencias existentes entre los argentinos que poseían todos los derechos inherentes a la condición de ciudadanos, y los que por su menor nivel educativo o por residir en lugares alejados como los espacios extraprovinciales no gozaban de idénticos beneficios. Más adelante reconocía que ya nada podía modificar la desigual situación, puesto que la raíz del problema se encontraba en los orígenes de la nacionalidad argentina: será una deficiencia de nuestra Constitución; pero nosotros no tenemos facultad para cambiarla. Tenemos que aceptar todos los resultados de la historia tal como ellos son, e incorporar, guiar hacia el mejor destino posible, haciendo uso de nuestras facultades superiores [...] es la responsabilidad de las clases dirigentes la que debemos mirat en el ejercicio de estos derechos, ya que, por selección natural, les corresponde esa especie de tutela sobre los que saben menos o pueden menos. ${ }^{33}$

Otros sectores nacionales identificados con tratadistas y juristas rebatían la visión pesimista de los que señalaban al habitante de los territorios de frontera como único responsable de su destino. Argumentaban que la incapacidad política de los territorianos $^{34}$ era única responsabilidad del Estado argentino que no había sido capaz de orientar el desempeño de los funcionarios designados ni de cumplir las disposiciones constitucionales que rompían el equilibrio que debía existir entre gobierno federal y gobiernos locales. ${ }^{35}$

En efecto, la nacionalización del espacio pampeano estuvo signada por una representación subjetiva e idílica de sus resultados. Existió un exagerado fervor patriótico orientado a reafirmar la territorialidad como una forma eficaz de fortalecer el papel de un Estado que asumía las riendas del postergado proceso de unificación nacional. Al finalizar la avanzada militar en el área pampeano-patagónica y en el momento de organizar la ocupación

${ }^{33}$ Botana, Repuiblica, 1997, pp. 655.

${ }^{34}$ Término aceptado para referirse a los habitantes de los Territorios Nacionales.

${ }^{35}$ Linares, Territorios, 1933, pp. 12-13. 
del impenetrable chaqueño, un militar de alto rango advertía que no debían repetirse los errores de la anterior experiencia, puesto que:

la división matemática de la tierra como un damero es irracional, reduce la capacidad receptiva del suelo y conspira contra su acertada y completa explotación [...] se deberán tener en cuenta varios factores que no se tuvieron en vista en el pasado, como ser: la calidad de las tierras y su destino más apropiado; la distancia a los puertos de embarque o a las estaciones de ferrocarril; la circunstancia de que por su topografía los campos fueran aprovechables para su explotación en verano e invierno; la abundancia y calidad de las aguas; las posibilidades de irrigación y otros factores que influyen sobre el rendimiento económico de la explotación y el empleo práctico a dar a las mismas tierras. ${ }^{36}$

Como ocurrió en otras regiones de América, la ocupación de la tierra en poder de grupos indígenas fue concebida como un recurso cultural para el mantenimiento de la identidad nacional. Se iniciaba una etapa caracterizada por la demarcación territorial como parte de la actividad centralizadora del Estado para construir el "cuerpo de la nación" y crear la abstracción de una nación palpable e imaginable. ${ }^{37}$ En este sentido, las tierras que surgían tras las incursiones militares se convertían ahora en la residencia autorizada de pobladores blancos y estos negociarían constantemente con el Estado el tipo de intervención para una sociedad en formación. Una prueba de ello fueron los

\footnotetext{
${ }^{36}$ Sarobe, Patagonia, 1935, p.119.

37 Mücke, "Desunión", 1999, y Smith, Cbosen, 2003, pp. 131-165.
}

tempranos reclamos autonómicos que esgrimieron los habitantes del Territorio Nacional de la Pampa quienes desde la primera década del siglo XX sostenían la conveniencia de autoadministrarse. ${ }^{38}$ Al mismo tiempo, el componente indígena desaparecía o se volvía invisible en los planes de los agentes estatales encargados de la colonización y administración de los Territorios Nacionales (véase mapa). ${ }^{39}$

\section{EL CONOCIMIENTO OFICIAL. Y CIENTÍFICO DEL TERRITORIO DE LA NACIÓN}

Ciertamente, la información existente al momento de emprender la ocupación de los territorios de la región pampeana fue insuficiente y fragmentaria. Las crónicas de los viajes de Pedro de Angelis, Thomas Falkner, Woodbine Parish y Charles Darwin resultaban incompletas y presentaban grandes vacíos cartográficos que requerían una reelaboración. A partir de esta certeza se reanudaron las exploraciones iniciadas en la primera mitad del siglo XIX. ${ }^{40}$

El proceso de producción de un conocimiento de las regiones conquistadas, expresado a través del desarrollo de la cartografía científica y de una geografía nacional, ayudó a crear una representación oficial del territorio de la nación. Además, legitimó el dominio estatal a través de una demarcación de límites para eliminar cual-

${ }^{38}$ Por autoadministración debe entenderse la capacidad de los diferentes grupos de interés locales para encontrar los mecanismos que eviten el desorden en el gobierno, en la justicia o en las finanzas. Carmagnani, "Territorios", 1994.

${ }^{39}$ Quijada, "Ciudadanización", 1999, y Argeri, "Mecanismos", 2001.

40 Nouzeilles, "Patagonia", 1999. 


\section{SECUENCIA}

Territorios nacionales

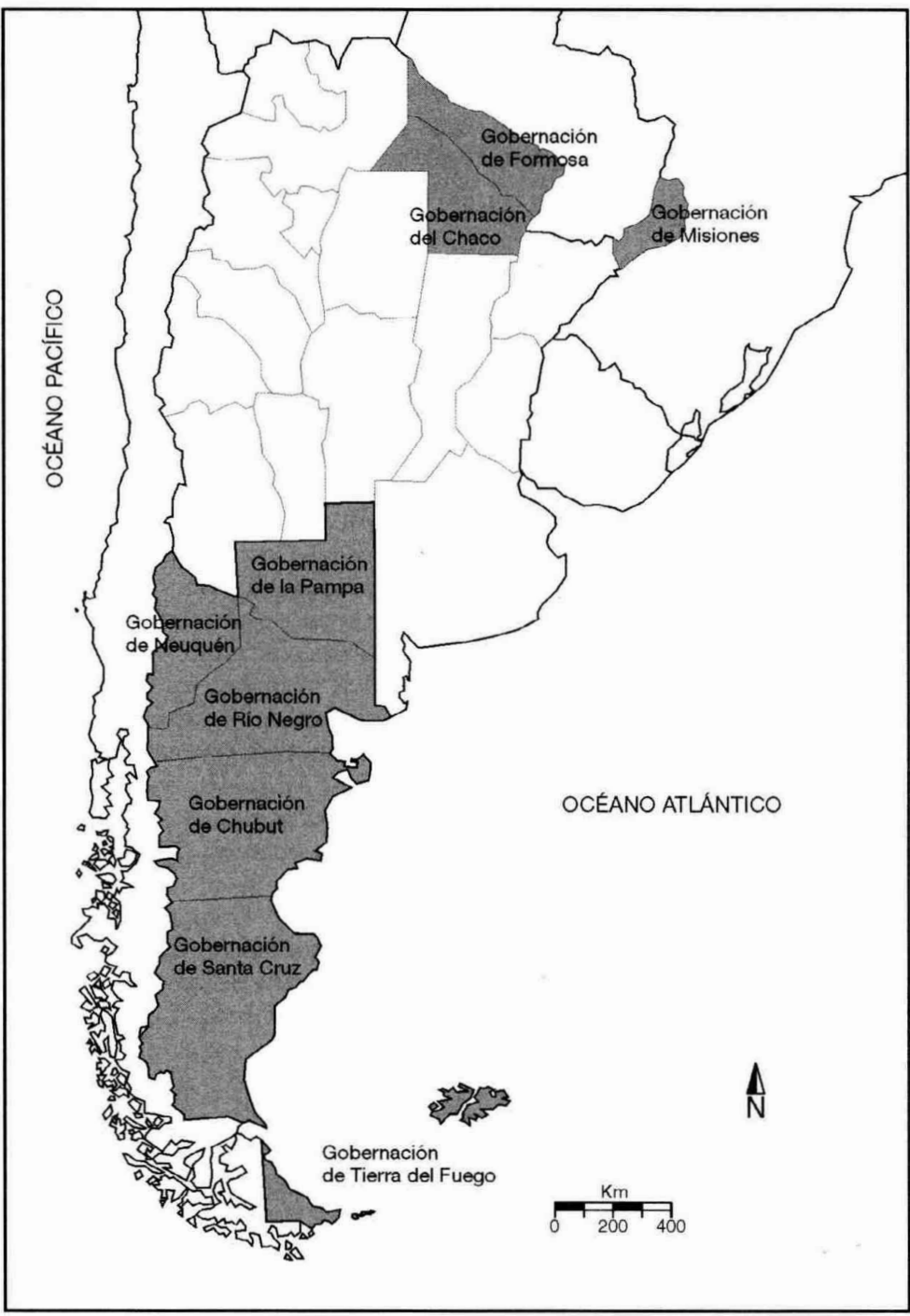

Fuente: elaboración propia con base en Sarobe, Patagonia, 1935. 
quier tipo de ambigüiedad con respecto a la soberanía territorial del país. Este conocimiento se efectuó a la par de la conformación política e histórica de los Territorios Nacionales. Desde el Estado se promovió y financió una serie de acciones públicas y privadas en un intento por difundir una imagen homogénea del territorio.

La representación del espacio fue, en gran parte, una creación ideológica que ubicaba a la elite intelectual como constructora y legitimadora del proyecto de ocupación de los espacios "vacíos". Bajo la sombra estatal, estos especialistas, en su mayoría miembros de los altos mandos militares, socializaban la información sobre los territorios de frontera y generaban un discurso asociado al progreso y a la civilización que desechaba las identidades tradicionales de los indígenas. El proceso de nacionalización de la frontera pampeana se realizó desde arriba hacia abajo. Desde el poder que otorgaba la pertenencia a una comunidad civilizada. ${ }^{41}$ Los miembros de la dirigencia argentina fueron partícipes de una densa red de relaciones entrecruzadas de solidaridades de clase, filiaciones políticas, ideológicas y profesionales que formaban un cerrado círculo político e intelectual. ${ }^{42}$

Se iniciaba una generación de especialistas civiles y militares en la descripción de las regiones que se encontraban fuera del dominio material de la nación, y de las que no se poseían conocimientos precisos. Esta corriente de exploradores se dedicó a investigar minuciosamente las características físicas y naturales de la Pampa, la Patagonia y el Gran Chaco. Realizaron las primeras descripciones de especies anima-

\footnotetext{
41 Lehmann-Nitsche, Problema, 1915, p. 3.

${ }^{42}$ Lois, "Desierto", 2004.
}

les y vegetales hasta entonces desconocidas en los ámbitos académicos nacionales.

Uno de los primeros trabajos orientados a la redefinición de las líneas fronterizas dedicado a proyectar la colonización al sur del río Salado fue escrito en el año 1816 por el militar Pedro Andrés García. En su obra Nuevo plan de fronteras se explicitaba un programa de actuación que preveía el avance de la frontera desde la provincia de Buenos Aires hasta el río Colorado, en la Patagonia y el río Diamante en Mendoza. El proyecto de García incluía, además de la incursión militar, la organización de expediciones científicas de reconocimiento tanto del terreno como de las comunidades indígenas. Para ello él proponía negociar y pactar con los indígenas de la región para evitar cualquier acción violenta que dificultara una futura relación pacífica entre unos y otros.

En este contexto de construcción y difusión de los conocimientos sobre la frontera interna, unos años después se publicaba La conquista de quince mil leguas (1878), y Viaje al país de los araucanos (1881) de Estanislao Zeballos. ${ }^{43}$ Ambas obras fueron escritas a petición del presidente Julio Roca, con el objeto de persuadir a los miembros del Congreso de la necesidad de invertir en infraestructura y aumentar el presupuesto de gastos para realizar la expedición militar. Zeballos aprovechó la oportunidad para autodefinirse como un "hombre de Estado" con una capacidad intelectual necesaria para administrar desde el gobierno los frutos de la incorporación de las tierras en poder de los indígenas. Para ello, proponía una gestión eficiente de los nuevos recursos disponibles in situ

\footnotetext{
${ }^{43}$ González, Estanislao, 1969, y Fernández y Navarro, "Zeballos", 2002.
} 
y reducir al mínimo las erogaciones presupuestarias destinadas al ordenamiento político y social de la nueva sociedad. Recomendaciones que no cayeron en saco roto, pues Estanislao Zeballos desempeñó importantes funciones militares y políticas durante esta etapa.

Como hemos adelantado, el conocimiento sobre el espacio pampeano se fue construyendo con cada campaña de exploración. En una primera etapa, realizadas por viajeros extranjeros originarios de España, Inglaterra, Alemania y Francia. A partir de la segunda mitad del siglo XIX, comenzaron a participar miembros de la elite intelectual y militar argentina que publicaban sus notas de viajes y descubrimientos con un cuidado estilo literario. Sus interpretaciones fueron divulgadas en libros, conferencias universitarias y en revistas científicas especialmente creadas para la circulación de las crónicas de la frontera. ${ }^{44} Y$ como señalaba una de estas publicaciones, el ánimo de sus editores era "vulgarizar los conocimientos geográficos y fomentar la exploración de los territorios desiertos de la república", 45 afirmaciones que sintetizaban el espíritu colonizador de la época.

La definitiva apropiación de las tierras de la frontera interior se vio favorecida por la combinación de dos factores. Por un lado, del desarrollo tecnológico-militar y de las comunicaciones. $Y$ en segundo lu-

${ }^{44}$ Entre estas destacaron los Anales de la Sociedad Cientifica Argentina desde 1876, el Boletín del Instituto Geográfico Argentina en 1879, los Anales Cientificos Argentinos que circuló desde 1874 hasta 1876, y la Revista de la Sociedad Geográfica Argentina en 1881. Auza, “Ocupación”, 1980, p. 62.

${ }^{45}$ Revista de la Sociedad Geográfica Argentina, t. I, 1881 , p. 2, en AGN. gar, gracias a las nuevas estrategias militares que aplicaban el conocimiento y las técnicas producidas por investigadores agrupados en instituciones y sociedades científicas al servicio del Estado. En un mensaje presidencial del año 1881 se aprecia el dispositivo de reconocimiento y exploración del terreno que contaba con el auxilio de científicos y técnicos contratados por el Estado:

Quince comisiones de agrimensores se ocupan igualmente de la medición y levantamiento de planos, con su correspondiente descripción topográfica, del territorio nacional [...] Una vez terminada esta operación podremos ofrecerlas al trabajo con exacta designación de los límites de cada lote, y de sus calidades agrícolas, despertando el interés universal por las facilidades de adquisición que se darían al comprador. [...] Total 44151 leguas, o sea, 110377500 hectáreas. ${ }^{46}$

El libro del coronel Álvaro Barros, Fronteras y territorios de las pampas del sur, fue publicado en el año 1872, y se inscribe entre las primeras obras destinadas a brindar instrucciones prácticas y a explicar estrategias para la ocupación definitiva de la frontera pampeana. El autor realizó una detallada descripción de la región en la que incluyó algunos aspectos referidos a la geología y la topografía. Además, el estudio incorporaba un minucioso inventario de los recursos naturales aprovechables de la zona. ${ }^{47}$ Del mismo modo, Adolfo Alsina, ministro de Guerra durante esta etapa, se abocó a escribir una serie de tratados en los que definía la estrategia militar

\footnotetext{
${ }^{46}$ Mabragaña, Mensajes, 1910, p. 29.

${ }^{47}$ Poggi, Álvaro, 1997.
} 
a seguir para detener los avances indígenas a las propiedades rurales bonaerenses. Una de las acciones más impactantes que $\mathrm{Al}$ sina proyectó durante su ministerio fue la construcción de la llamada "zanja de Alsina”, encargada al ingeniero francés Alfredo Ebelot. 48

La elaboración de un conocimiento oficial y científico de la frontera interior respondió a un claro interés político con el objeto de establecer una conciencia territorial $^{49}$ y facilitar así el ansiado progreso que presagiaba la dirigencia nacional y del que se consideraban los únicos artífices posibles. $^{\text {so }}$

Hacia finales del siglo XIX y comienzos del Xx, se extiende en Argentina un espacio público donde los conocimientos científicos acerca de los recursos y características de los territorios de la frontera adquieren una proyección y valoración social cuya expresión más acabada fue la creación de museos naturales y antropológicos. Además, la participación en congresos internacionales y la publicación de cartas geográficas y topográficas tenían el objetivo de clarificar el dominio intelectual sobre las fronteras interiores.

${ }^{48}$ La obra pretendía rodear con un foso de $610 \mathrm{ki}-$ lómetros la línea que separaba los fortines militares de la frontera interior. El proyecto original fue abandonado en mitad de su elaboración, afectado por la escasez de recursos humanos y económicos para su continuación y conservación por lo que la extensión definitiva fue de 374 kilómetros. Luzuriaga, "Precursor", 1980.

${ }^{49}$ Expresión utilizada para referirse a la apropiación material del espacio como una forma de adecuar la Argentina real a la Argentina política reconocida internacionalmente. Auza, "Ocupación", 1980, pp. 83-86.

${ }^{50}$ González, Civilidad, 2001.
Las exploraciones realizadas en el espacio pampeano no sólo se limitaban al estudio de la naturaleza del lugar, sino que además propiciaban el análisis de las características antropológicas y físicas de las comunidades indígenas que allí habitaban. ${ }^{51}$ Las conclusiones de estos trabajos, imbuidos del auge positivista del siglo XIX, no hacían más que legitimar un discurso que intentaba justificar biológicamente la inferioridad de los indios. Se valoraban costumbres y hábitos según principios científicos de carácter evolucionista y racista que revelaban el desconocimiento y desinterés por la cultura de los pueblos originarios. ${ }^{52}$ En este contexto, la ciudad se convertía en la máxima expresión de civilidad y esta se imaginaba como un ensayo de estabilidad y ciudadanía donde antes sólo existían nómadas. El interés político de erigir ciudades donde antes habitaban los indígenas se reflejaba en el discurso presidencial de Julio Roca, cuando señalaba: "es indispensable la acción eficaz de la nación para dotar a esos grandes vacíos de núcleos de población, que, una vez radicados y prósperos, han de convertirse en verdaderos focos de atracción". 53

Algunos sectores minoritarios intentaban rebatir los argumentos xenófobos y argumentaban el carácter racional de los indígenas, así por ejemplo, en el año 1870 , Lucio Mansilla, político, militar y escritor de la época, publicaba Una excursión a los indios ranqueles. Esta obra constituyó una de las pocas crónicas en la que se rechazaba la ideología de la superioridad racista y darwiniana. Las afirmaciones de Mansilla no bastaron para modificar una

\footnotetext{
${ }^{51}$ Navarro, "Salvaje", 2001.

52 Scarzanella, Gringos, 2002.

${ }^{53}$ Mabragaña, Mensajes, 1910, p. 34.
} 
política desordenada que ensayaba diferentes alternativas de solución, a medida que crecía el número de indígenas expulsados violentamente de sus comunidades.

\section{LA POLÍTICA ESTATAL DE DISTRIBUCIÓN Y REPARTO DE TIERRAS}

La apropiación de la tierra dejó paso al reparto y/o venta de las parcelas y con ello llegó el consecuente proceso de colonización y puesta en producción. En el año 1876, durante el gobierno de Avellaneda, se sancionó la Ley de Colonización, que estuvo vigente por más de cuatro décadas sin modificación y rigió cerca de 60 años el proceso de ocupación y distribución de tierras en Argentina. ${ }^{54}$ Esta legislación dirigió la distribución y ocupación del suelo, y otorgaba al Estado argentino la potestad definitiva sobre las tierras fuera de los límites de las catorce provincias fundacionales. Finalmente, se lograba un territorio unificado y la satisfacción por la llegada de la "civilización" a las pampas. Este fue el espíritu que dominaba el discurso de fin de siglo, y así lo expresaba uno de sus representantes:

¡He aquí la Pampa regenerada! Ayer debía ser pavorosa por su soledad, en la cual vagaba la vista sin hallar un punto de socorro cuando brotaban los indios de su seno como salen los avestruces de sus pajonales. Hoy la soledad va cediendo su imperio a la población,

${ }^{54}$ La Ley de Colonización de 1876 o Ley Avellaneda unificó la legislación de tierras para todo el país e intentó poner en funcionamiento una serie de organismos estatales encargados de aplicar programas relacionados con la inmigración y la colonización de la tierra pública. Zeberio, "Mundo", 1999. el miedo a la barbarie ha desaparecido, para siempre, después de tres siglos de sangrientas luchas, la extensión está dominada por el alambre eléctrico y silba a su puerta la locomotora, mientras que la ciencia la invade y escudriña iluminando sus arcanos. ¡ $\mathrm{He}$ aquí la Pampa regenerada! ${ }^{5 s}$

Una vez finalizada la expedición militar se formalizó la creación de la Dirección de Tierras y Colonias, organismo estatal encargado de realizar la mensura, loteo de las tierras y promoción de la colonización tanto en Buenos Aires como en Europa. Las operaciones se efectuaron mediante la oferta de venta de 4000 títulos de tierras de 10000 hectáreas la unidad de medida por cada título. Esta oferta pública no significó la inmediata radicación de la población en el territorio pampeano, y así lo entendieron las instancias de poder nacional: "la inmigración espontánea no irá a los extremos desiertos del país sino llevada por la mano de la nación y con ventajas y concesiones liberales". ${ }^{56}$ Antes era necesario suministrar una importante inversión estatal en obra pública destinada a la construcción de caminos y líneas férreas para conectar los nuevos núcleos de población con el centro político nacional y para transportar la producción a los puertos de Buenos Aires, Bahía Blanca y Rosario.

La primera distribución de tierras benefició a los miembros del ejército conquistador y a sus herederos. El reparto se efectuó de acuerdo con la jerarquía militar de cada miembro y merced a la Ley de Premios al Ejército Expedicionario de 1885. Los protagonistas de la Campaña del Desierto recibieron distintas unidades de su-

\footnotetext{
"s Zeballos, Viaje, 1934, pp. 78-79.

${ }^{56}$ Mabragaña, Mensajes, 1910, p. 172.
} 
perficie como recompensa a su labor en la lucha contra el indio. Inicialmente no se especificó el emplazamiento preciso de los predios otorgados por no estar finalizada la mensura total del territorio. En su lugar, se entregaron títulos provisorios que fueron canjeados por los definitivos una vez que finalizó el proceso de loteo y valoración productiva de las tierras. ${ }^{57}$

Desde el comienzo de la ocupación de las tierras, no existió un sistema regular y planificado de colonización, ni una tarea de fiscalización por parte del Estado. Esta situación generó un movimiento especulativo que fue característico de la primera etapa de colonización. Según los datos del precio de la tierra pública, entre los años 1888-1890, el valor por hectárea en la región pampeana se incrementó de 1.80 a 9.65 pesos. La consecuencia directa fue la restricción de la propiedad de la tierra a aquellos sectores que carecían de capacidad adquisitiva y que llegaban desde las provincias con expectativas de obtener grandes extensiones de tierras a bajo precio.

Este patrón de distribución generó un reducido núcleo de empresarios, hacendados bonaerenses, militares, burócratas y comerciantes, que independientemente de su origen acumularon grandes riquezas en propiedades rurales. ${ }^{58}$ En definitiva, el reparto de tierras evidenció el gran fracaso que significó la Ley Avellaneda, llamada a ser el puntal en que se apoyaría el desarrollo agropecuario de los nuevos territorios.

En un intento por revertir la concentración de propiedades, en el año 1916, con la Unión Cívica Radical ${ }^{59}$ en el poder,

57 Mayol, "Captura", 1995.

58 Zeberio, "Tierra", 2002, pp. 129-155.

${ }^{59} \mathrm{La}$ Unión Cívica Radical se coronaba con un régimen electoral democrático en las elecciones de 1916. comenzaron a manifestarse algunas propuestas para la revisión y estudio del régimen de propiedad, del sistema de tenencia y del uso de la tierra. Las modificaciones estaban orientadas principalmente a promover la colonización, basada en la pequeña propiedad cercana a centros urbanos, estaciones ferroviarias y puertos. ${ }^{60} \mathrm{El}$ radicalismo estimaba que la nueva redistribución de tierras provocaría cambios en la racionalidad productiva del agricultor y favorecería el arraigo a la tierra ya no del hombre solo, sino del grupo familiar. Con estas medidas se intentaba zanjar un debate político cuya solución estaba estrechamente ligada a incrementar el número de pobladores en los Territorios Nacionales y a combatir la creciente urbanización de algunas capitales de provincia.

A pesar de la declaración de intenciones de los dirigentes radicales en materia de tierra pública, el grupo político se enfrentó a la oposición de los grandes pro-

Hipólito Yrigoyen asumió la presidencia de Argentina el 12 de octubre de 1916 hasta el año 1922 en que lo sucedió Marcelo T. de Alvear. En 1928 fue reelegido y fue depuesto por un alzamiento militar el 6 de septiembre de 1930. En opinión de algunos historiadores la asunción de Yrigoyen puede catalogarse como la culminación del largo proceso de modernización emprendido por la sociedad argentina desde mediados del siglo XIX. Romero, Breve, 2001, pp. 15-65.

${ }^{60}$ Los intentos de reformas y reparación del régimen de tenencia de la tierta crecen cuando el radicalismo ocupa el gobierno nacional, aunque la falta de definición del oficialismo, sumada a una férrea oposición legislativa de socialistas y conservadores y a una situación internacional adversa de la economía agroexportadora terminan por anular cualquier modificación significativa sobre este aspecto, y el fervor inicial de la Unión Cívica Radical sólo es concebido en términos del discurso político más que en sólidas bases para el cambio en materia de adquisición de tierras fiscales. 
ductores que gozaban del derecho de tenencia y disfrute de las tierras resultantes de la expropiación indígena. Estos se opusieron sistemáticamente a retrotraer el dominio de sus propiedades al Estado o a la subdivisión de las mismas. Finalmente, el gobierno se limitó a suspender la adjudicación de nuevas tierras en propiedad y a arrendar a título precario las tierras vacantes de los Territorios Nacionales. En definitiva, las condiciones tradicionales del régimen agrario que el Estado pretendía modificar persistieron sin cambios, aun en periodos de desajustes y crisis de la economía agroexportadora argentina. ${ }^{61}$

\section{CONCLUSIONES}

La nacionalización de las tierras de la frontera pampeana se inscribe en el largo proceso histórico de formación del Estado nacional, cuando este se instituye en un actor significativo del cambio que atravesó la sociedad argentina a finales del XIX.

La incorporación a la economía mundial de vastas y desconocidas extensiones de tierra que se encontraban fuera del dominio estatal exigió la implementación de una serie de políticas públicas para alcanzar un mayor crecimiento socioeconómico que traería aparejado la modernización y el desarrollo social. Todo ello estaba asentado en la maximización de un recurso abundante que permanecía "desaprovechado" en manos de las comunidades indígenas: las tierras de la frontera interior. La gestión requería un análisis del costo hipotético que la empresa representaba y una evaluación objetiva de las reales capacida2003.

61 Zeberio, "Utopía", 1991, y Girbal, "Riqueza”, 
desarrollo y terminó por relajar el vínculo que enlazaba al Estado argentino con la sociedad que se conformó tras la nacionalización de la frontera pampeana.

\section{FUENTES CONSULTADAS}

\section{Archivos}

AGN Archivo General de la Nación.

BCN Biblioteca del Congreso de la Nación. República Argentina.

BSTJ Biblioteca del Superior Tribunal de Justicia de La Pampa.

\section{Bibliografía}

-Abrams, Philip, Historical Sociology, Cornell University Press, Ithaca, 1994.

-Alberdi, Juan Bautista, Bases y puntos de partida para la organización política de la República Argentina, Estrada, Buenos Aires, 1943.

-Argeri, María, "Mecanismos políticos y expropiación de las sociedades indígenas pampeano-patagónicas, Río Negro (1880-1930)", Quinto Sol. Revista de Historia Regional, UNLPAM, año 5 , núm. 5, 2001, pp. 13-43.

- De guerreros a delincuentes. La desarticulación de las jefaturas indígenas y el poder judicial. Norpatagonia, 1880-1930, Consejo Superior de Investigación Científica, Madrid, 2005 (Tierra Nueva E Cielo Nuevo).

-Auza, Tomás, "La ocupación del espacio vacío: de la frontera interior a la frontera exterior, 1876-1910" en Gustavo Ferrari y Ezequiel Gallo (comps.), La Argentina. Del ochenta al centenario, Sudamericana, Buenos Aires, 1980, pp. 62-83.

-Bertoni, Lilia Ana, Patriotas, cosmopolitas y nacionalistas. La construcción de la nacionalidad argentina a fin-de-siglo (1880-1910), FCE, Buenos Aires, 2001.
-Botana, Natalio, De la República posible a la República verdadera (1880-1910), Ariel-Historia, Buenos Aires, 1997 (Biblioteca del Pensamiento Argentino).

Buenos Aires, 1997.

-Bragoni, Beatriz, "Gobierno elector, mercado de influencias y dinámicas políticas provinciales en la crisis política argentina del ' 90 (Mendoza, 1888-1892)", Entrepasados, núms. 24-25, 2003, pp. 67-99.

-Brennan, James y Ofelia Pianetto, Region and Nation: Politics, Economy and Society in Twentieth-Century Argentina, St. Martin's Press, Nueva York, 2000.

-Carmagnani, Marcelo, "Territorios, provincias y estados: las transformaciones de los espacios políticos en México, 1750-1850" en Josefina Vázquez (coord.), La fundación del Estado mexicano, 1821-1855, Nueva Imagen, México, 1994, pp. 39-74.

-Castellán, Ángel, "Nacimiento historiográfico del término desierto", Congreso Nacional de Historia sobre la Conquista del Desierto, Academia Nacional de la Historia, Buenos Aires, 1980, t. IV, pp. 293-307.

-Chiaramonte, José Carlos, Nación y Estado en Iberoamérica: el lenguaje político en tiempos de las independencias, Sudamericana, Buenos Aires, 2004.

-Devoto, Fernando, Nacionalismos, fascismo y tradicionalismo en la Argentina moderna. Una bistoria, Siglo XXI, Buenos Aires, 2002.

-Dodds, Klaus John, "Geography, Identity and the Creation of the Argentine State", Bulletin of Latin American Research, vol. 12, núm. 3, 1993, pp. 311-331.

-Drayton, Richard, Nature's Government, Yale University Press, New Haven y Londres, 2000.

-Eberle, Adriana y Claudia Iribarren, "Estrategias del Estado nacional conducentes a la incorporación del indio a la sociedad civil. Constantes e innovaciones, 1904-1943", 11 I Congreso Argen- 
tino de Americanistas, Actas de la Sociedad Argentina de Americanistas, Buenos Aires, 2000, t. II, pp. 161-185.

-Evans, Peter, Dietrich Rueschemeyer y Theda Skocpol, Bringing the State Back In, Cambridge University Press, Cambridge, 1999.

-Fernández, Sandra y Fernando Navarro, "Zeballos, la parábola de la narración. El estudio de la región del trigo como libro de viaje" en I encuentro Las Metáforas del Viaje y sus Imágenes. La Literatura de Viajeros como Problema, Rosario, 2002.

-Gadano, José Enrique, Territorios Nacionales. Estudio político-económico, Abeledo, Buenos Aires, 1945.

-Garavaglia, Juan Carlos, "Economic Growth and Regional Differentiatios: The River Plate Region at the End of the Eighteenth-Century", Hispanic American Historical Review, núm. 65, vol. 1, 1985, pp. 51-89.

-Girbal de Blacha, Noemí, "Riqueza, poder y control social. Acerca de las estrategias empresariales agrarias en la Argentina (1900-1950)", Anuario IEHS, núm. 18, 2003, Tandil, pp. 367-395.

-González Arrili, Bernardo, Estanislao Zeballos. Ensayo biográfico, Academia Nacional de la Historia, Buenos Aires, 1969.

-González Bernaldo de Quirós, Pilar, Civilidad y política en los orígenes de la nación argentina. Las sociabilidades en Buenos Aires, 1829-1862, FCE, Buenos Aires, 2001.

-Guérin, Miguel, "Consecuencias de la conquista en el Territorio Nacional de La Pampa" en Congreso de Historia sobre la Conquista del Desierto, Academia Nacional de la Historia, 1980, t. III, pp. 451-465.

-Halperin Donghi, Tulio, Historia contemporánea de América Latina, Alianza, Madrid, 1975. , Proyecto y construcción de una nación,

Biblioteca Ayacucho, Venezuela, 1980.

-Hora, Roy, "Empresarios rurales y política en la Argentina, 1880-1916" en Hilda Sabato y
Alberto Lettieri (comps.), La vida política en Argentina del siglo XIX. Armas, votos y voces, FCE, Buenos Aires, 2003, pp. 293-310.

-Lehmann-Nitsche, Robert, El problema indígena. Necesidad de destinar territorios reservados a los indígenas de la Patagonia, Tierra del Fuego y Chaco, según el proceder de los Estados Unidos de Norte América, Imprenta de Coni Hnos., Buenos Aires, 1915.

-Linares Quintana, Segundo, Los Territorios Nacionales ante la Constitución y la ley, Talleres Gráficos Porter, Buenos Aires, 1933.

-Lois, Carla, "De desierto ignoto a territorio representado. Cartografía, Estado y territorio en el Gran Chaco argentino (1866-1916)", Cuadernos del Territorio, Instituto de Geografía/Facultad de Filosofía y Letras-Universidad de Buenos Aires, núm. 10, 2004, Buenos Aires.

-Luzuriaga, Aníbal, "Un precursor civil: el ingeniero Alfredo Ebelot" en Congreso Nacional de Historia sobre la Conquista del Desierto, Academia Nacional de la Historia, Buenos Aires, 1980, t. IV, pp. 195-207.

-Lluch, Andrea, "Un largo proceso de exclusión. La política oficial y el destino final de los indígenas ranquelinos en La Pampa: Colonia Emilio Mitre", Quinto Sol. Revista de Historia Regional, UNLPAM, año 6, núm. 6, 2002, pp. 43-69.

-Mabragaña, Heraclio, Los mensajes. Historia del desenvolvimiento de la nación argentina redactada cronológicamente por sus gobernantes, 1810-1910, Talleres Gráficos de la Compañía General de Fósforos, Buenos Aires, 1910.

-Maluendres, Sergio, "De condicionantes y posibilidades: los agricultores del sureste productivo del Territorio Nacional de La Pampa" en Raúl Mandrini (coord.), Huellas en la tierra. Indígenas, bacendados y agricultores en la Pampa de los siglos XVI al XX, IEHS-UNICEN, Tandil, 1993, pp. 289-323.

-, "Los agricultores de los márgenes de la región pampeana: mitos y 'realidades'. El 
caso del Territorio Nacional de La Pampa" en Mónica Bjerg y Andrea Reguera (comps.), Problemas de la bistoria agraria. Nuevos debates y perspectivas de investigación, IEHS, Tandil, 1995, pp. 183-209.

-Mandrini, Raúl, "Desartollo de una sociedad indígena pastoril en el área interserrana bonaerense", Anuario IEHS, núm. 2, 1987, Tandil, pp. 71-98.

-Mayo, Carlos, "Riel, sociedad y frontera. El ferrocarril de la Pampa Central (1881-1887)" en Congreso Nacional de Historia sobre la Conquista del Desierto, Academia Nacional de la Historia, Buenos Aires, 1980, t. III, pp. 553-571.

-Mayol, Anamaría, "La captura de un espacio" en Julio Colombato (coord.), Trillar era una fiesta. Poblamiento y puesta en producción de la Pampa territoriana, Universidad Nacional de La Pampa, Santa Rosa, 1995, t. 1, pp. 15-21.

-Moroni, Marisa, "El delicado equilibrio entre la ley y el orden en la etapa de nacionalización de los territorios de frontera. El Territorio Nacional de la Pampa, Argentina", Revista Complutense de Historia de América, Universidad Complutense de Madrid, vol. 31, 2005, España, pp. 177-191.

-Mücke, Ulrich, "La desunión imaginada. Indios y nación en el Perú decimonónico", Jabrbuch fiur Geschichte Lateinamerikas, vol. 36, 1999, pp. 219-232.

-Navarro Floria, Pedro, "Un país sin indios. La imagen de la Pampa y la Patagonia en la geografía del naciente Estado argentino", Scripta Nova, núm. 51, 1999, Barcelona.

___, "El salvaje y su tratamiento en el discurso político argentino sobre la frontera sur, 1853-1879", Revista de Indias, vol. LXI, 2001, Madrid, pp. 345-376.

-Nouzeilles, Gabriela, "Patagonia as Borderland: Nature, Culture and the Idea of State", Journal of Latin American Cultural Studies, vol. 8, núm. 1, 1999, pp. 35-48.
-Oszlak, Oscar, La formación del Estado argentino, Planeta, Buenos Aires, 1999.

-Palermo, Miguel Ángel, "La innovación agropecuaria entre los indígenas pampeano-patagónicos. Génesis y procesos", Anuario IEHS, núm. 3, 1988, Tandil, pp. 43-90.

-Paredes, Rogelio, "Las cuentas del diablo. Expectativas sobre eficiencia, beneficio y represión en la obra de Estanislao Zeballos (18781881)", IX Jornadas Interescuelas/Departamentos de Historia, Córdoba, 24 al 26 de septiembre de 2003.

-Poggi, Rinaldo, Alvaro Barros en la frontera sur. Contribución al estudio de un argentino olvidado, Fundación Nuestra Historia, Buenos Aires, 1997.

-Quijada, Mónica, "La ciudadanización del 'indio bárbaro'. Políticas oficiales y oficiosas hacia la población de la Pampa y la Patagonia, 18701920", Revista de Indias, vol. LIX, núm. 217, 1999, pp. 675-704.

- Elites intelectuales y modelos colectivos: mundo ibérico, XV-XIX, Instituto de Historia-CSIC, Madrid, 2002.

—, "Repensando la frontera sur argentina: concepto, contenido, continuidades y discontinuidades de una realidad espacial y étnica", Revista de Indias, vol. LXII, núm. 224, 2002, Madrid, pp. 103-142.

$\longrightarrow$, Carmen Bernand y Arnd Schneider, Homogeneidad y nación con un estudio de caso: Argentina, siglos XIX y XX, CSIC, Madrid, 2001.

-Riekenberg, Michael, “Aniquilar hasta su exterminio a estos indios... Un ensayo para repensar la frontera bonaerense (1770-1830)", Ibero-Americana Pragensia, vol. xxx, 1996, pp. 61-75.

-Romero, José Luis, Breve bistoria contemporánea de la Argentina, FCE, Buenos Aires, 2001.

-Rueschemeyer, Dietrich y Theda Skocpol, State, Social Knowledge and the Origins of Modern Social Policies, Princeton University Press, New Jersey, 1996. 
-Sabato, Hilda y Alberto Lettieri (comps.), La vida política en Argentina del siglo XIX. Amas, votos y voces, FCE, Buenos Aires, 2003.

-Sarobe, José María, La Patagonia y sus problemas: estudio geográfico, económico, político y social de los Territorios Nacionales del sur, Ed. Aniceto López, Buenos Aires, 1935.

-Scarzanella, Eugenia, Ni gringos ni indios. Inmigración, criminalidad y racismo en Argentina. 1890-1940, Universidad Nacional de Quilmes, Buenos Aires, 2002.

-Sempat Assadourian, Carlos, "El sector exportador de una economía regional del interior argentino. Córdoba, 1800-1860", Nova Americana, núm. 1, 1978, pp. 57-104.

-Smith, Anthony, Cbosen Peoples. Sacred Sources of National Identity, Oxford University Press, Nueva York, 2003.
-Tilly, Charles, Coerción, capital y los Estados europeos, 990-1990, Alianza, Madrid, 1992.

-Zeballos, Estanislao, Viaje al país de los araucanos, Talleres Gráficos Argentinos, Buenos Aires, 1934.

-Zeberio, Blanca, "La utopía de la tierra en el Nuevo Sud: explotaciones agrícolas, trayectorias y estrategias productivas de los agricultores (1900-1930)", Anuario IEHS, núm. 6, 1991, Tandil, pp. 81-112.

—_ "Un mundo rural en cambio", Nueva historia argentina, Sudamericana, Buenos Aires, 1999, vol. Iv.

_. "Tierra, familia y herencia en la Pampa argentina. Continuidades y rupturas en la reproducción del patrimonio (siglos XIX-XX)", Quinto Sol. Revista de Historia Regional, UNLPAM, año 6, núm. 6, 2002, pp. 129-155. 